Check for updates

Cite this: Chem. Commun., 2018, 54,4286

Received 22nd January 2018, Accepted 3rd April 2018

DOI: $10.1039 / \mathrm{c} 8 \mathrm{cc} 00526 \mathrm{e}$

rsc.li/chemcomm

\section{$\left[{ }^{18}\right.$ F]fluoro-benziodoxole: a no-carrier-added electrophilic fluorinating reagent. Rapid, simple radiosynthesis, purification and application for fluorine-18 labelling $\dagger$}

\author{
Miguel A. Cortés González, (D) a Patrik Nordeman, ${ }^{b}$ Antonio Bermejo Gómez, (D) ac \\ Denise N. Meyer, (D) a Gunnar Antoni, ${ }^{b}$ Magnus Schou ${ }^{c}$ and Kálmán J. Szabó (DD *a
}

Operationally simple radiosynthesis and purification of $\left[{ }^{18} \mathrm{~F}\right]$ fluorobenziodoxole was developed starting from a cyclotron produced $\left[{ }^{18} \mathrm{~F}\right] \mathrm{F}^{-}$precursor, $\left[{ }^{18} \mathrm{~F}\right] \mathrm{TBAF}$, and tosyl-benziodoxole. The synthetic utility of $\left[{ }^{18} \mathrm{~F}\right]$ fluoro-benziodoxole was demonstrated by electrophilic fluorocyclization of o-styrilamides proceeding with high RCC (typically 50-90\%) and high molar activity (up to $396 \mathrm{GBq}_{\mu} \mathrm{mol}^{-1}$ ).

Organofluorine compounds ${ }^{1}$ are widely used in pharmaceutical ${ }^{2}$ and agrochemical ${ }^{3}$ industries as well as in medical diagnostics. ${ }^{4}$ The foremost radionuclide in Positron Emission Tomography (PET) is fluorine-18 because of its half-life of 109.8 minutes, the strong $\mathrm{C}-\mathrm{F}$ bonding and the usually high metabolic stability of organofluorines. ${ }^{4}$ The optimal conditions for synthesis of organofluorines with the natural isotope fluorine-19 and those containing the radioactive isotope fluorine- 18 are often fundamentally different. An important challenge in radiochemistry is to obtain ${ }^{18} \mathrm{~F}$-labelled organofluorine species in high radiochemical conversion (RCC) and at high molar activity within the lifetime of fluorine-18. Traditionally, high molar activity could only be achieved by nucleophilic ${ }^{18} \mathrm{~F}$-fluorination reactions. ${ }^{4}$ Electrophilic fluorination reactions target the realm of electron-rich functional groups, such as alkenes and aromatics with electron supplying substituents. ${ }^{1}$ A characteristic feature of an electrophilic fluorinating reagent is the ability to accept an electron pair to their low-lying LUMO orbital having a substantial AO contribution from the fluorine atom, i.e. the fluorine-18 functional group in the reagent is electron deficient. A trivial example for such an electrophilic fluorination reagent is $\left[{ }^{18} \mathrm{~F}\right] \mathrm{F}_{2}$. However, this reagent is difficult to handle in radiosynthesis, very reactive (thus unselective) and it cannot be obtained with high molar activity. ${ }^{5}$ Unfortunately, most of the selective electrophilic fluorination reagents, such as $\left[{ }^{18}\right.$ F $]$ NFSI (Fig. 1a), ${ }^{6}\left[{ }^{18}\right.$ F $]$ Selectfluor ${ }^{7}$ and related species ${ }^{8}$ are also

\footnotetext{
${ }^{a}$ Department of Organic Chemistry, Stockholm University, SE-106 91, Sweden. E-mail: kalman.j.szabo@su.se; Web: http:/www.organ.su.se/ks/

${ }^{b}$ Department of Medicinal Chemistry, Uppsala University, SE-751 23, Sweden ${ }^{c}$ AstraZeneca PET Centre at Karolinska Institutet, SE-171 76, Stockholm, Sweden $\dagger$ Electronic supplementary information (ESI) available: Experimental procedures, characterization, radiochemistry and spectral data. See DOI: 10.1039/c8cc00526e
}

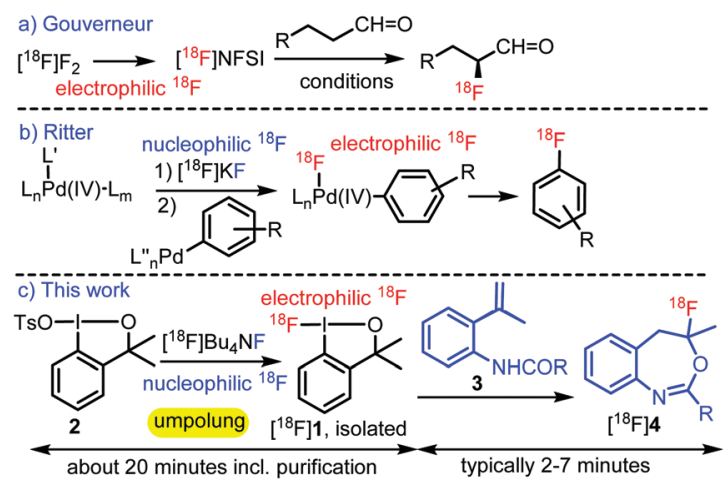

Fig. 1 Methods for electrophilic ${ }^{18} \mathrm{~F}$-labelling.

prepared from $\left[{ }^{18} \mathrm{~F}\right] \mathrm{F}_{2}$, which usually leads to unsatisfactory molar activities via rather cumbersome radiosynthetic procedures. On the other hand $\left[{ }^{18} \mathrm{~F}\right] \mathrm{F}^{-}$based reagents, such as $\left[{ }^{18} \mathrm{~F}\right] \mathrm{KF}$ or $\left[{ }^{18} \mathrm{~F}\right] \mathrm{TBAF}$ can be generated with high fluorine-18 molar activity.

However, these $\left[{ }^{18} \mathrm{~F}\right] \mathrm{F}^{-}$based reagents have an explicit nucleophilic reactivity, as the electron rich $\mathrm{F}^{-}$has an electron donating character. Construction of an electrophilic fluorinating reagent from $\left[{ }^{18} \mathrm{~F}\right] \mathrm{F}^{-}$requires the so-called "umpolung" of the reactivity. Ritter and co-workers ${ }^{9}$ have constructed an electrophilic fluorination reagent from a $\mathrm{Pd}(\mathrm{Iv})$ complex and $\left[{ }^{18} \mathrm{~F}\right] \mathrm{KF}$ (Fig. 1b). In the applied ligand exchange process the $\mathrm{K}-\left[{ }^{18} \mathrm{~F}\right] \mathrm{F}$ interaction was transformed into $\mathrm{Pd}(\mathrm{Iv})-\left[{ }^{18} \mathrm{~F}\right] \mathrm{F}$ bonding. Change of the potassium counterion to a palladium(Iv) center rendered the electron-rich fluorine-18 to an electron deficient one. Thus, the subsequent reductive elimination from the $\operatorname{Pd}(\mathrm{Iv})$ complex created a new $\left[{ }^{18} \mathrm{~F}\right] \mathrm{F}$-carbon bond. A similar process was developed using Ni(III) complexes as well. ${ }^{10}$ However, the widespread use of these methods has been limited by the complexity of the synthesis of the $\mathrm{Pd}(\mathrm{Iv})$ and $\mathrm{Ni}(\mathrm{III})$ complexes.

Safe, easy to handle and stable fluoro-benziodoxole reagent 1 was first reported by Prévost and Legault in $2012,{ }^{11}$ and since then it has become a privileged fluorinating reagent. ${ }^{12}$ Recent DFT modelling studies ${ }^{13}$ discussed the mechanistic aspects of 
the electrophilic fluorination reactions by this hypervalent iodine reagent. Notably, fluoro-iodane 1 can easily be synthesized from anionic fluorine precursors. ${ }^{12 c, 14}$ Considering the importance of bridging the gap between the recent methodological advances in fluorine-19 chemistry and the high demand to access new types of fluorine-18 PET tracers for clinical diagnostics, ${ }^{15}$ we decided to develop a new methodology for rapid radiosynthesis of electrophilic $\left[{ }^{18} \mathrm{~F}\right]$ fluoro-benziodoxole $\left(\left[{ }^{18} \mathrm{~F}\right] \mathbf{1}\right)$ reagent from standard $\left[{ }^{18} \mathrm{~F}\right] \mathrm{F}^{-}$precursors (Fig. 1c).

Our fluorine-19 experiments have shown that the synthesis of 1 from commonly used benziodoxole precursors, such as $\mathrm{OH}$, OAc and halogenide derivatives requires relatively long reaction times (0.5-4 h). Therefore, the highly reactive (yet bench-stable) tosyl derivative $2^{12 c}$ was selected as precursor for the radiosynthesis. Reagent 1 partially or completely decomposes under chromatography due to the high affinity of the iodine bound fluorine to $\mathrm{Si}, \mathrm{Al}$ and alkali metal ions. Indeed, over $95 \%$ of $\left[{ }^{18} \mathrm{~F}\right] \mathbf{1}$ was lost, when we attempted to purify it on silica or alumina adsorbents $(\mathrm{ESI}, \dagger \mathrm{S} 12)$. Therefore, the analysis and purification of $\left[{ }^{18} \mathrm{~F}\right] \mathbf{1}$ cannot be achieved by chromatographic methods, as fluoro-iodines $\mathbf{1}$ and $\left[{ }^{18} \mathrm{~F}\right] \mathbf{1}$ decomposed when subjected to reverse-phase HPLC, TLC or paper chromatography. The alternative purification method was based on the relatively good solubility of $\mathbf{1}$ in hexane. According to our fluorine-19 experiments the starting materials tosyl-benziodoxole (2) and TBAF, as well as the inorganic compounds formed in the synthesis of $\mathbf{1}$ are insoluble in hexane. Thus, after the allotted times (Table 1) we evaporated the solvent (DCM) of the reaction mixture of 2 and $\left[{ }^{18} \mathrm{~F}\right] \mathrm{Bu}_{4} \mathrm{NF}$, and then the solid residue was extracted with hexane. We assumed that the entire amount of the radioactivity of the hexane solution arose from $\left[{ }^{18} \mathrm{~F}\right] \mathbf{1}$, and this radioactivity was the basis of the calculation of RCC (Table 1). To get further evidence for the formation of $\left[{ }^{18} \mathrm{~F}\right] \mathbf{1}$ we studied

Table 1 Fluorination of 2 with $\left[^{18}{\mathrm{~F}] B u_{4} N F^{a}}^{a}\right.$

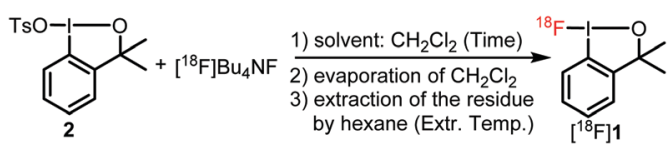

\begin{tabular}{llrrrr}
\hline Entry & Temp. $\left({ }^{\circ} \mathrm{C}\right)$ & Time $(\mathrm{min})$ & $\mathbf{2}(\mathrm{mg})$ & Extr. temp. $\left({ }^{\circ} \mathrm{C}\right)$ & RCC $(\%)$ \\
\hline 1 & 70 & 40 & 5 & 70 & $47 \pm 3(n=2)$ \\
2 & 70 & 20 & 5 & 70 & $40 \pm 7(n=2)$ \\
3 & 70 & 20 & 20 & 70 & $42 \pm 6(n=2)$ \\
$4^{b}$ & 70 & 20 & 5 & 70 & $37 \pm 1(n=2)$ \\
$5^{c}$ & 70 & 20 & 5 & 70 & $56 \pm 1(n=2)$ \\
6 & RT & 20 & 5 & 70 & $40 \pm 3(n=2)$ \\
7 & RT & 5 & 5 & 70 & $\mathbf{4 1} \pm \mathbf{1}(n=2)$ \\
8 & RT & 5 & 5 & 40 & $23 \pm 3(n=2)$ \\
9 & RT & 5 & 5 & RT & $20 \pm 2(n=2)$ \\
10 & RT & 5 & 0 & 70 & $7 \pm 1(n=2)$ \\
11 & RT & 5 & 0 & 40 & $10 \pm 4(n=2)$ \\
12 & RT & 5 & 0 & RT & $5 \pm 2(n=2)$
\end{tabular}

${ }^{a} 2(12 \mu \mathrm{mol})$ and $\left[{ }^{18} \mathrm{~F}\right] \mathrm{Bu}_{4} \mathrm{NF}$ were mixed in $\operatorname{DCM}(500 \mu \mathrm{L})$ and stirred at the indicated temperature and time. The solvent was removed under a $\mathrm{N}_{2}$ stream. To the obtained solid residue was added hexane $(500 \mu \mathrm{L})$ and stirred for 1 minute at the given temperatures (Extr. temp.). The extracted activity indicates the percentage of total activity extracted in the hexane phase as average of two experiments $(n=2) .{ }^{b} 250 \mu \mathrm{L}$ of DCM instead of $500 \mu \mathrm{L} .{ }^{c} 1000 \mu \mathrm{L}$ of DCM instead of $500 \mu \mathrm{L}$. DCM $=$ dichloromethane. the chemical composition of a decayed sample of $\left[{ }^{18} \mathrm{~F}\right] \mathbf{1}$ by ${ }^{19}$ F-NMR and HRMS. Such analysis takes advantage of the inevitable co-production of unlabeled 1, which is formed by the reaction of 2 with the minute amounts of fluorine-19 that is present in the reaction mixture. Indeed, our analysis of the decayed sample of $\left[{ }^{18} \mathrm{~F}\right] \mathbf{1}$ confirmed both by ${ }^{19} \mathrm{~F}-\mathrm{NMR}$ and HRMS the presence of $\left[{ }^{19} \mathrm{~F}\right] \mathbf{1}$ in the hexane extract (ESI, $\dagger$ S9-S12), which is diagnostic of the formation of $\left[{ }^{18} \mathrm{~F}\right] \mathbf{1}$ and its extraction to hexane. Interestingly, TBAF was not detected in the ${ }^{19} \mathrm{~F}-\mathrm{NMR}$ spectrum of the decayed sample indicating that the extracted sample did not contain significant contamination of $\left[{ }^{18} \mathrm{~F}\right] \mathrm{Bu}_{4} \mathrm{NF}$.

We have carefully optimized the reaction temperature, time and concentration of the reaction of 2 and $\left[{ }^{18} \mathrm{~F}\right] \mathrm{TBAF}$ and the temperature for the extraction with hexane (Table 1). Initially, we carried out the reactions in DCM (typically $500 \mu \mathrm{L}$ ) at $70{ }^{\circ} \mathrm{C}$ (entries 1-5). Using $5 \mathrm{mg}$ of 2 the RCC of $\left[{ }^{18} \mathrm{~F}\right] 1$ was similar $(40-47 \%)$ after 40 and 20 minutes of reaction time (entries 1 and 2). Increasing the amount of 2 (entry 3) or increasing the concentration of the reactants (by reducing the amount of solvent, entry 4) did not change significantly the RCC (42\% and $37 \%$ respectively). Contrarily, decreasing the concentration (entry 5) led to increasing of RCC (56\%), albeit an elongated time for the evaporation of DCM (entry 5). Therefore, we kept the solvent volume at $500 \mu \mathrm{L}$ in the subsequent experiments. It was found that the RCC was nearly unchanged when the reaction was carried out at room temperature instead of $70{ }^{\circ} \mathrm{C}$ (entry 6). Moreover, the reaction time could be shortened to five minutes without decreasing the RCC (41\%, entry 7$)$ thus reducing significantly the duration of the radiosynthesis of $\left[{ }^{18} \mathrm{~F}\right] \mathbf{1}$.

In the above procedures (entries 1-7), we employed $70{ }^{\circ} \mathrm{C}$ for the extraction of the solid residue that remained after the evaporation of DCM. Decreasing the extraction temperature to $40{ }^{\circ} \mathrm{C}$ or room temperature (entries 8 and 9) led to significant decrease of the RCC (20-23\%). The optimal procedure (entry 7 ) involves the reaction of 2 and $\left[{ }^{18} \mathrm{~F}\right] \mathrm{TBAF}$ in $500 \mu \mathrm{L}$ DCM ( 5 minutes at room temperature); then evaporation of DCM and extraction of the solid residue by hexane for one minute at $70{ }^{\circ} \mathrm{C}$.

As mentioned above, the fluorine-19 experiments showed that TBAF is insoluble in hexane. To confirm this observation, we made a further control experiment using $\left[{ }^{18} \mathrm{~F}\right] \mathrm{TBAF}$. We carried out the above optimized three-step procedure without employing 2 (entry 10). The radioanalysis indicated 7\% RCC for the extracted inorganic fluoride. The extracted amounts of $\left[{ }^{18} \mathrm{~F}\right]$ fluoride were about the same by varying the extraction temperature (entries 11 and 12). These experiments (together with the fluorine-19 results) confirmed that the above three-step procedure results in high purity sample of $\left[{ }^{18} \mathrm{~F}\right] \mathbf{1}$ with very low (if at all) contamination of $\left[{ }^{18} \mathrm{~F}\right]$ TBAF. Notably, the chemical stability of $\mathbf{1}^{12 c}$ allows for centralized large-scale production and subsequent shipment of $\left[{ }^{18} \mathrm{~F}\right] \mathbf{1}$ to PET centers that lack an on-site cyclotron.

In order to demonstrate the radiosynthetic utility of purified $\left[{ }^{18} \mathrm{~F}\right] \mathbf{1}$ for ${ }^{18} \mathrm{~F}$-labelling we performed electrophilic ${ }^{13}$ fluorocyclization reactions of $o$-styrilamides 3. Gulder and co-workers ${ }^{12 b, k}$ have shown that using equimolar amounts of $\mathbf{3}$ and $\mathbf{1}$ a rapid fluorocyclization can be performed at room temperature resulting in fluorobenzoxazepines bearing a quaternary fluoride. 
Radiosynthesis of $\left[{ }^{18} \mathrm{~F}\right] \mathbf{4}$ was performed by adding the hexane solution of $\left[{ }^{18} \mathrm{~F}\right] \mathbf{1}$ to a solution of precursor $\mathbf{3}$ in acetonitrile followed by evaporation of the solvents. Subsequently, the solid residue was dissolved in acetonitrile $(500 \mu \mathrm{L})$ and the fluorocyclization reaction was studied at different temperatures and reaction times (Table 2). Using the optimal fluorocyclization conditions reported by Gulder for the reaction with fluorine$19^{12 b}$ (using 3a and 1), we obtained low but encouraging (9\% RCC) levels of the fluoro-benzoxazepines product $\left[{ }^{18} \mathrm{~F}\right] \mathbf{4 a}$ (Table 2, entry 1). Increasing the temperature from room temperature to $90{ }^{\circ} \mathrm{C}$ and decreasing the reaction time from

Table 2 Electrophilic fluorocyclization affording $\left[{ }^{18} \mathrm{~F}\right]$ fluoro-benzoxazepines ${ }^{a}$

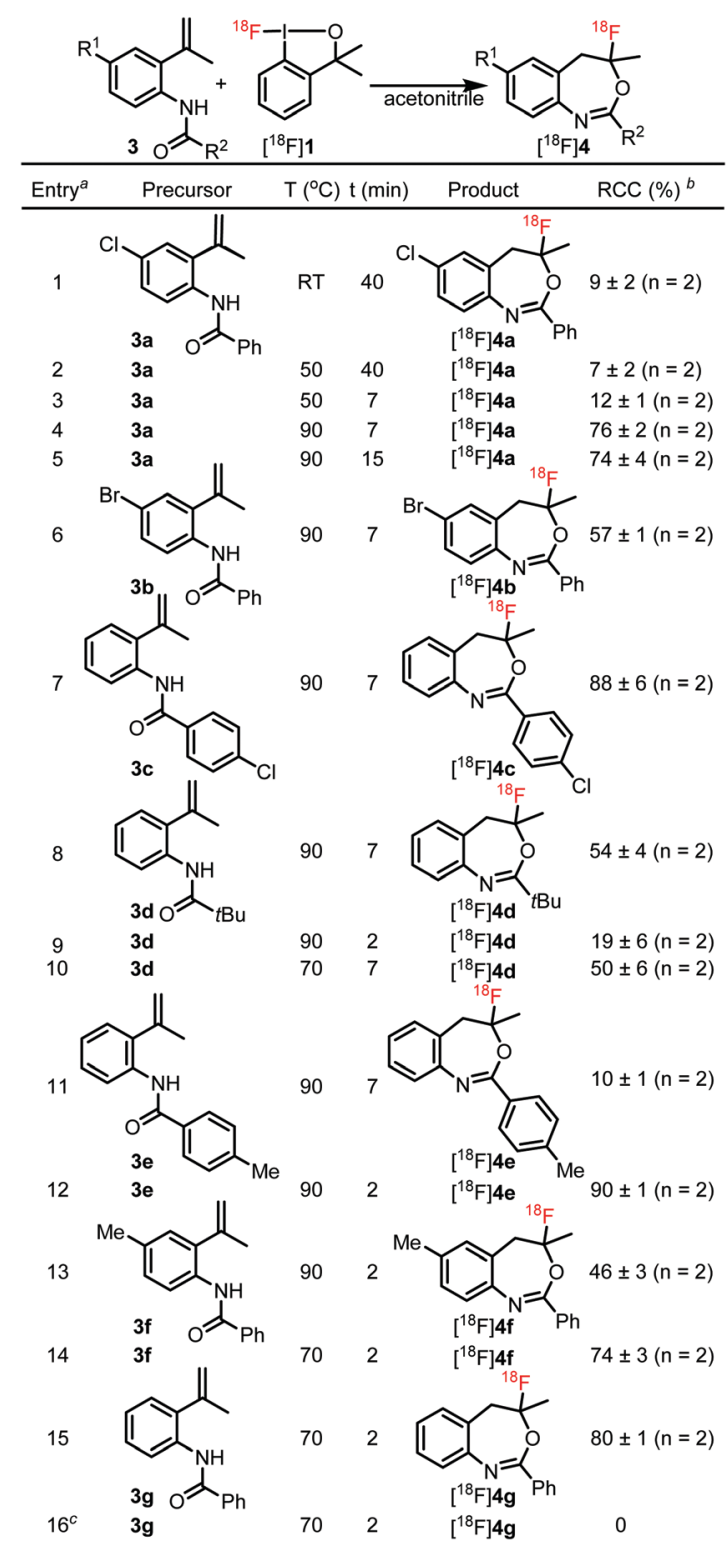

${ }^{a}$ To a solution of 3 in $\mathrm{MeCN}(0.4 \mu \mathrm{mol}, 25 \mu \mathrm{L})$ was added $\left[{ }^{18} \mathrm{~F}\right] \mathbf{1}$ in hexane $(50-100 \mu \mathrm{L})$. The mixture was evaporated and re-dissolved in $\operatorname{MeCN}(500 \mu \mathrm{L})$ before heating at the indicated temperatures and times. ${ }^{b}$ Estimated by radio-HPLC of the crude reaction mixture starting from $\left[{ }^{18} \mathrm{~F}\right] 1$. ${ }^{c}$ Using $\left[{ }^{18} \mathrm{~F}\right] \mathrm{Bu}_{4} \mathrm{NF}$ instead of $\left[{ }^{18} \mathrm{~F}\right] \mathbf{1}$.
40 minutes to 7 minutes led to a significant increase of the RCC to $76 \%$ (entries $2-4$ ). Further elongation of the reaction time did not improve the RCC ( $74 \%$, entry 5$)$. The bromo analog $\mathbf{3 b}$ and the isomeric chloro $o$-styrilamide $3 \mathbf{c}$ reacted under identical conditions affording the corresponding fluoro-benzoxazepines $\left[{ }^{18} \mathrm{~F}\right] \mathbf{4 b}$ and $\left[{ }^{18} \mathrm{~F}\right] \mathbf{4}$ in 57 and $88 \%$ RCC (entries 6 and 7). Using these conditions, ${ }^{t} \mathrm{Bu}$ amide $\left[{ }^{18} \mathrm{~F}\right] \mathbf{4 d}$ was obtained in $54 \%$ RCC along with an unidentified ${ }^{18} \mathrm{~F}$-labeled impurity (28\%). This impurity was probably a decomposition product resulting from the chemical instability of $\left[{ }^{18} \mathrm{~F}\right] \mathbf{4 d}$. Decreasing the reaction temperature to $70{ }^{\circ} \mathrm{C}$ led to an RCC of $50 \%$ (entry 10) with reduction of the labeled impurity to $20 \%$. When $3 \mathbf{e}$, having a more electron rich nitrogen than $\mathbf{3 c}$, was reacted with $\left[{ }^{18} \mathrm{~F}\right] \mathbf{1}$ under identical conditions, the RCC of $\left[{ }^{18} \mathrm{~F}\right] \mathbf{4 e}$ was much lower $(10 \%$, entry 11$)$ than for $\left[{ }^{18} \mathrm{~F}\right] \mathbf{4 c}(88 \%$, entry 7$)$. A possible reason can be the relatively low chemical stability of $\left[{ }^{18} \mathrm{~F}\right] \mathbf{4 e}$ at elevated temperatures. When the reaction time was decreased from seven to two minutes, the RCC increased to $90 \%$ (entry 12). The electrophilic fluorination of the electron-rich alkene in $\mathbf{3 f}$ is probably faster than for its electron-poor counterparts in $\mathbf{3 a - b}$ (entries 4 and 6 ), but product $\left[{ }^{18} \mathrm{~F}\right] \mathbf{4 f}$ has low thermostability compared to $\left[{ }^{18} \mathrm{~F}\right] \mathbf{4 a}-\mathbf{b}$. Accordingly, the RCC for the formation of $\left[{ }^{18} \mathrm{~F}\right] \mathbf{4 f}$ was relatively low at $90{ }^{\circ} \mathrm{C}(46 \%$, entry 13$)$. However, when the reaction temperature was decreased to $70{ }^{\circ} \mathrm{C}$ the RCC was increased to $74 \%$ (entry 14). The parent $o$-styrilamide $3 \mathrm{~g}$ reacted also smoothly at $70{ }^{\circ} \mathrm{C}$ in 2 minutes affording $\left[{ }^{18} \mathrm{~F}\right] \mathbf{4 g}$ with $80 \%$ of RCC. A final confirmation that the nucleophilic fluorination reagent $\left[{ }^{18} \mathrm{~F}\right] \mathrm{TBAF}$ is not able to perform fluorocyclization is demonstrated by entry 16 . When $3 \mathrm{~g}$ was reacted with $\left[{ }^{18} \mathrm{~F}\right] \mathrm{TBAF}$ instead of $\left[{ }^{18} \mathrm{~F}\right] \mathbf{1}$ formation of $\left[{ }^{18} \mathrm{~F}\right] \mathbf{4 g}$ was not observed. This control experiment also proved that even if small amounts of $\left[{ }^{18} \mathrm{~F}\right] \mathrm{TBAF}$ would have contaminated the purified sample of $\left[{ }^{18} \mathrm{~F}\right] \mathbf{1}$, it was not able to perform fluorocyclization of $o$-styrilamides 3.

We also performed one-pot reactions without isolation and purification of $\left[{ }^{18} \mathrm{~F}\right] \mathbf{1}$ (Fig. 2). When the one-pot reaction was performed in two sequential steps: (1) in situ formation of $\left[{ }^{18} \mathrm{~F}\right] \mathbf{1}$ followed by (2) fluorocyclization of $\mathbf{3 a}$ the reaction time was shorter by about 5 minutes than for the version with purified $\left[{ }^{18} \mathrm{~F}\right] \mathbf{1}$ (Table 2 , entry $4, \mathrm{RCC}=76 \%$ ). However, the RCC in the one-pot reaction was poor: $14 \%$ and $34 \%$ based on $\left[{ }^{18} \mathrm{~F}\right] \mathrm{Bu}_{4} \mathrm{NF}$ or $\left[{ }^{18} \mathrm{~F}\right] \mathbf{1}$ as limiting reagent, respectively (Fig. 2). These results confirm that radiosynthetic attempts for using in situ generated $\left[{ }^{18} \mathrm{~F}\right] \mathbf{1}$ proceed with inferior results compared to the above method with purified $\left[{ }^{18} \mathrm{~F}\right] \mathbf{1}$ reagent. ${ }^{12 j}$

The optimized protocol was employed for the determination of the isolated yield (RCY) and the molar activity. In this reaction $3.93 \mathrm{GBq}$ of $\left[{ }^{18} \mathrm{~F}\right] \mathrm{Bu}_{4} \mathrm{NF}$ were reacted with 2 affording

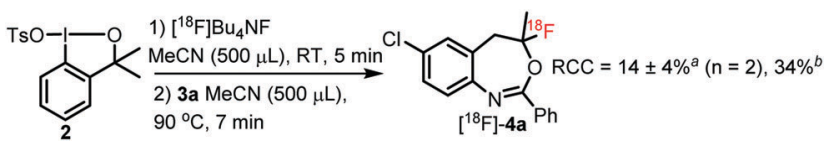

Fig. 2 One-pot approach for the synthesis of $\left[{ }^{18} \mathrm{~F}\right] 4 \mathrm{a}$. ${ }^{a} \mathrm{RCC}$ based on $\left[{ }^{18} \mathrm{~F}\right] \mathrm{Bu} \mathrm{u}_{4} \mathrm{NF}$ as limiting reagent; ${ }^{b} \mathrm{RCC}$ based on $\left[{ }^{18} \mathrm{~F}\right] \mathbf{1}$ assuming that it formed with $41 \%$ RCC (Table 1, entry 7 ). 
$904 \mathrm{MBq}$ of $\left[{ }^{18} \mathrm{~F}\right] \mathbf{1}$, which was used for the labelling of $\mathbf{3 a}$ in $\mathrm{MeCN}$ at $90{ }^{\circ} \mathrm{C}$ for 7 minutes. The reaction resulted in $92.4 \mathrm{MBq}$ of $\left[{ }^{18} \mathrm{~F}\right] \mathbf{4 a}$ (with $>99 \%$ radiochemical purity) corresponding to $10 \%$ isolated activity yield (RCY) and a molar activity of $396 \mathrm{GBq} \mu \mathrm{mol}^{-1}{ }^{4 c}$ This molar activity is in the range of the values obtained for tracers by nucleophilic fluorination in our laboratories and orders of magnitude higher than the corresponding values reported for the electrophilic fluorination methods based on application of $\left[{ }^{18} \mathrm{~F}\right] \mathrm{F}_{2} \cdot{ }^{6-8}$ The overall time of the reaction from the bombardment to isolation of the $\left[{ }^{18} \mathrm{~F}\right]$ fluorobenzoxazepine product was about two hours, of which the radiosynthesis and purification of $\left[{ }^{18} \mathrm{~F}\right] \mathbf{1}$ from $\left[{ }^{18} \mathrm{~F}\right] \mathrm{TBAF}$ was achieved in about 20 minutes. This method was not automatized, and thus proper automatization may further improve the efficiency of fluorine-18 labelling by $\left[{ }^{18} \mathrm{~F}\right] \mathbf{1}$ in clinical applications.

In summary, we have presented a new radiosynthetic method for the preparation of the electrophilic fluorination reagent $\left[{ }^{18} \mathrm{~F}\right] \mathbf{1}$ from a nucleophilic $\left[{ }^{18} \mathrm{~F}\right] \mathrm{F}^{-}$precursor, $\left[{ }^{18} \mathrm{~F}\right] \mathrm{TBAF}$. The reaction and purification of $\left[{ }^{18} \mathrm{~F}\right] \mathbf{1}$ could be performed by an operationally simple three-step process within about 20 minutes. The purified $\left[{ }^{18} \mathrm{~F}\right] \mathbf{1}$ reagent was free from the excess of its precursor $\mathbf{2}$ and may contain only traces of $\left[{ }^{18} \mathrm{~F}\right] \mathrm{TBAF}$. Since $\mathbf{1}$ is chemically stable for an indefinite time, the purified $\left[{ }^{18} \mathrm{~F}\right] \mathbf{1}$ is even transportable in hexane solution to PET facilities that lack on-site cyclotrons. We have also demonstrated the synthetic utility of $\left[{ }^{18} \mathrm{~F}\right] \mathbf{1}$ for electrophilic fluorocyclization of $o$-stryrilamides. The reactions could be performed in 2-7 minutes with typically high RCC. The preparative scale experiments led to a product with $396 \mathrm{GBq} \mu \mathrm{mol}^{-1}$ of molar activity, which is higher than the molar activity typically obtained in electrophilic ${ }^{18} \mathrm{~F}$-labelling experiments. We will continue in our laboratories the studies of exploitation of $\left[{ }^{18} \mathrm{~F}\right] \mathbf{1}$ in further ${ }^{18} \mathrm{~F}$-labelling applications and development of further hypervalent iodine based ${ }^{18} \mathrm{~F}$-fluorination/alkylfluorination reagents.

Support by the Stockholm Brain Institute, VINNOVA and the Swedish Research Council (VR) is gratefully acknowledged. We thank Mihály Szabó for his valuable help in some of the fluorine-19 experiments.

\section{Conflicts of interest}

There are no conflicts to declare.

\section{Notes and references}

1 (a) T. Liang, C. N. Neumann and T. Ritter, Angew. Chem., Int. Ed., 2013, 52, 8214; (b) J. Charpentier, N. Früh and A. Togni, Chem. Rev., 2015, 115, 650 .
2 (a) J. Wang, M. Sánchez-Roselló, J. L. Aceña, C. del Pozo, A. E. Sorochinsky, S. Fustero, V. A. Soloshonok and H. Liu, Chem. Rev., 2014, 114, 2432; (b) Y. Zhou, J. Wang, Z. Gu, S. Wang, W. Zhu, J. L. Aceña, V. A. Soloshonok, K. Izawa and H. Liu, Chem. Rev., 2016, 116, 422.

3 P. Jeschke, ChemBioChem, 2004, 5, 570.

4 (a) P. W. Miller, N. J. Long, R. Vilar and A. D. Gee, Angew. Chem., Int. Ed., 2008, 47, 8998; (b) S. Preshlock, M. Tredwell and V. Gouverneur, Chem. Rev., 2016, 116, 719; (c) D. van der Born, A. Pees, A. J. Poot, R. V. A. Orru, A. D. Windhorst and D. J. Vugts, Chem. Soc. Rev., 2017, 46, 4709.

5 E. L. Cole, M. N. Stewart, R. Littich, R. Hoareau and P. J. H. Scott, Curr. Top. Med. Chem., 2014, 14, 875.

6 (a) F. Buckingham, A. K. Kirjavainen, S. Forsback, A. Krzyczmonik, T. Keller, I. M. Newington, M. Glaser, S. K. Luthra, O. Solin and V. Gouverneur, Angew. Chem., Int. Ed., 2015, 54, 13366; (b) H. Teare, E. G. Robins, E. Arstad, S. K. Luthra and V. Gouverneur, Chem. Commun., 2007, 2330.

7 (a) I. S. R. Stenhagen, A. K. Kirjavainen, S. J. Forsback, C. G. Jorgensen, E. G. Robins, S. K. Luthra, O. Solin and V. Gouverneur, Chem. Commun., 2013, 49, 1386; (b) H. Teare, E. G. Robins, A. Kirjavainen, S. Forsback, G. Sandford, O. Solin, S. K. Luthra and V. Gouverneur, Angew. Chem., Int. Ed., 2010, 49, 6821.

8 (a) N. Satyamurthy, G. T. Bida, M. E. Phelps and J. R. Barrio, Int. J. Radiat. Appl. Instrum., Part A. Appl. Radiat. Isot., 1990, 41, 733; (b) R. Chirakal, N. Vasdev, G. J. Schrobilgen and C. Nahmias, J. Fluorine Chem., 1999, 99, 87.

9 E. Lee, A. S. Kamlet, D. C. Powers, C. N. Neumann, G. B. Boursalian, T. Furuya, D. C. Choi, J. M. Hooker and T. Ritter, Science, 2011, 334, 639.

10 E. Lee, J. M. Hooker and T. Ritter, J. Am. Chem. Soc., 2012, 134, 17456.

11 C. Y. Legault and J. Prévost, Acta Crystallogr., Sect. E: Struct. Rep. Online, 2012, 68, o1238.

12 (a) S. V. Kohlhepp and T. Gulder, Chem. Soc. Rev., 2016, 45, 6270; (b) A. Ulmer, C. Brunner, A. M. Arnold, A. Pöthig and T. Gulder, Chem. - Eur. J., 2016, 22, 3660; (c) G. C. Geary, E. G. Hope, K. Singh and A. M. Stuart, Chem. Commun., 2013, 49, 9263; (d) G. C. Geary, E. G. Hope and A. M. Stuart, Angew. Chem., Int. Ed., 2015, 54, 14911; (e) N. O. Ilchenko, B. O. A. Tasch and K. J. Szabó, Angew. Chem., Int. Ed., 2014, 53, 12897; $(f)$ W. Yuan and K. J. Szabó, Angew. Chem., Int. Ed., 2015, 54, 8533; $(g)$ W. Yuan, L. Eriksson and K. J. Szabó, Angew. Chem., Int. Ed., 2016, 55, 8410; $(h)$ N. O. Ilchenko, M. A. Cortés and K. J. Szabo, ACS Catal., 2016, 6, 447; (i) N. O. Ilchenko, M. Hedberg and K. J. Szabo, Chem. Sci., 2017, 8, 1056; $(j)$ B. Yang, K. Chansaenpak, H. Wu, L. Zhu, M. Wang, Z. Li and H. Lu, Chem. Commun., 2017, 53, 3497; ( $k$ ) C. Brunner, A. Andries-Ulmer, G. M. Kiefl and T. Gulder, Eur. J. Org. Chem., 2018, DOI: 10.1002/ejoc.201800129.

13 (a) J. Zhang, K. J. Szabo and F. Himo, ACS Catal., 2017, 7, 1093; (b) B. Zhou, T. Yan, X.-S. Xue and J.-P. Cheng, Org. Lett., 2016, 18, 6128; (c) T. Yan, B. Zhou, X.-S. Xue and J.-P. Cheng, J. Org. Chem., 2016, 81, 9006.

14 V. Matoušek, E. Pietrasiak, R. Schwenk and A. Togni, J. Org. Chem., 2013, 78, 6763.

15 (a) M. G. Campbell, J. Mercier, C. Genicot, V. Gouverneur, J. M. Hooker and T. Ritter, Nat. Chem., 2017, 9, 1; (b) M. S. Sanford and P. J. H. Scott, ACS Cent. Sci., 2016, 2, 128; (c) Z. Yuan, R. Cheng, P. Chen, G. Liu and S. H. Liang, Angew. Chem., Int. Ed., 2016, 55, 11882; (d) A. K. Podichetty, S. Wagner, S. Schröer, A. Faust, M. Schäfers, O. Schober, K. Kopka and G. Haufe, J. Med. Chem., 2009, 52, 3484; (e) E. E. Gray, M. K. Nielsen, K. A. Choquette, J. A. Kalow, T. J. A. Graham and A. G. Doyle, J. Am. Chem. Soc., 2016, 138, 10802; $(f)$ X. Huang, W. Liu, H. Ren, R. Neelamegam, J. M. Hooker and J. T. Groves, J. Am. Chem. Soc., 2014, 136, 6842. 